\title{
FORMAS DE APRENDIZAGEM E SABERES NO TRABALHO DE MANICURES
}

\author{
FORMS OF LEARNING AND KNOWLEDGE IN THE WORK OF MANICURES
}

\author{
Recebido em 21.08.2015. Aprovado em 18.02.2016 \\ Avaliado pelo sistema double blind review \\ DOI: http://dx.doi.org/10.12712/rpca.v10i1.655
}

\section{Shalimar Gallon}

shalimargallon@hotmail.com

Universidade Federal do Rio Grande do Sul (UFRGS), Porto Alegre/RS, BRASIL

\section{Betina Magalhães Bitencourt}

betina.mb@gmail.com

Universidade Estadual do Rio Grande do Sul (UFRGS), Porto Alegre/RS, BRASIL

\section{Daniela Dietz Viana}

danidietz@gmail.com

Universidade Federal do Rio Grande do Sul (UFRGS), Porto Alegre/RS, BRASIL

\section{Claudia Simone Antonello}

claudia.antonello@ufrgs.br

Universidade Federal do Rio Grande do Sul (UFRGS), Porto Alegre/RS, BRASIL

\section{Resumo}

As discussões a respeito da importância do trabalho são crescentes em nossa sociedade. Ela se mobiliza a fim de atender interesses econômicos, legitimando determinadas profissões como mais importantes. Com o objetivo de superar essa concepção, analisamos ofícios que contribuem para a sociedade, mas não possuem o mesmo valor social percebido. Estudamos o conhecimento adquirido no exercício de determinado trabalho e como ocorre a aprendizagem por meio das práticas, baseados na ideia que todo tipo de ação produz conhecimento. A investigação para o presente estudo desenvolveu-se em dois salões de beleza, na cidade de Porto Alegre (RS), nos quais trabalham sete manicures, no total. O estudo foi realizado por meio de observação não participante e de entrevistas não estruturadas, no período de dezembro de 2011 a março de 2012. Identificou-se que as profissionais adaptam a maioria das técnicas ensinadas no curso de manicure. Isso significa que cada indivíduo tem seu jeito de exercer o próprio trabalho, não havendo uma única maneira certa de realizá-lo. O jeito de cada manicure desempenhar suas atividades só é descoberto na prática, quando ela aplica seu conhecimento. Tal processo produz novo conhecimento e nova prática, uma vez que as ações tanto são sustentadas pela prática como a constituem.

Palavras-chave: Aprendizagem Baseada em Práticas. Abordagem da Estética. Abordagem Cultural. Manicures. Saberes no Trabalho.

\footnotetext{
Abstract

Discussions over the importance of the work are increasing in our society. Nevertheless, certain professionals are legitimized as the most important ones according to economic interests. In order to overcome this conception, we analyze a profession that contribute to society, but do not have the same perceived social value. We study the knowledge acquired in the performance of a particular job and how learning occurs through the practices, based on the assumption that every type of action produces knowledge. The investigation was carried out into two beauty salons in the city of Porto Alegre (RS), in which work seven manicures, in the total. The study was conducted through non-participant observation and not structured interviews, in the period December 2011 to March 2012. It was identified that the professionals adapt most of the techniques taught in the course of manicure. This means that each individual has his way of exercising own work, there is not a right way to do it. The way each manicure plays their activities is only discovered in practice, when she applies her knowledge. This process produces new knowledge and new practice, once actions are both underpinned and constituted by practice.
}

Keywords: Practice-based Learning. Aesthetic Approach. Cultural Approach. Manicures. Knowledge at Work. 


\section{INTRODUÇÃO}

O trabalho tem importante papel na vida dos indivíduos, cuja realização está relacionada com o sentido que cada um lhe atribui. Ele também possui caráter utilitário e se apresenta como a afirmação da identidade do ser humano, por meio das atribuições individuais mobilizadas na realização da tarefa (DEJOURS, 2008). O trabalho é importante na vida das pessoas e da sociedade, por ser um meio de integração social.

Independente da tarefa exercida, o trabalho adquire um sentido diferente para cada indivíduo. A sociedade valoriza determinados tipos de trabalho em função da representatividade que possuem. Por exemplo, a atividade de um médico é mais valorizada que outras em função do status que esta profissão possui e pelo tempo que estes profissionais dedicam à sua formação. De modo contrário, o ofício de um garçom não possui o mesmo prestígio. Vivemos em uma sociedade na qual a preocupação com a utilidade é facilmente perceptível, sendo necessário que o profissional seja eficaz e produtivo financeira e socialmente, para que seu trabalho seja valorizado (GAULEJAC, 2007).

Cada profissão exige diferente saberes. Garçons, cabeleireiros, jardineiros, marceneiros, entre outros possuem conhecimento e técnica desenvolvida, assim como os que exercem profissões elitizadas. Rose (2007) mostra que precisamos analisar com cuidado certos ofícios, pois há consequências amplas e inevitáveis na capacidade de raciocínio dos indivíduos que os executam. O trabalho demanda que o ser humano desenvolva habilidades e requer esforço para exercê-lo. Toda a ação realizada está embasada em um conhecimento que, ao ser exposto, evidencia os saberes dos indivíduos, pois o trabalho são os saberes em prática; é o conhecimento posto em prática (GHERARDI, 2006). Assim, quando não valorizamos as funções com baixo prestígio social, podemos "obscurecer as nuances e variações das experiências individuais de trabalho, assim como as diferenças reais existentes no ambiente físico e social de cada local de trabalho, impedindo-nos, com isso, de ver por inteiro a complexidade da vida de trabalho" (ROSE, 2007, p. 44).

O conhecimento pode emergir das práticas, sinalizando sua 'naturalização' tanto no modo habitual e repetido de fazer, como no conhecimento desenvolvido do fazer. Ou seja, o saber e o fazer não estão separados (NICOLINI; GHERARDI; YANOW, 2003; ROSE, 2007), pois a prática e o conhecimento técnico não estão dissociados. Qualquer indivíduo necessita de conhecimento para produzir uma ação e, ao produzir essa ação, também adquire conhecimento.

Nesse contexto, o presente estudo analisa as diferentes formas de aprendizagem que ocorrem durante a prática de um trabalho específico: a profissão de manicure, abrangendo também a de pedicure. Apreciada pelo embelezamento das mãos e dos pés, esta profissão exige conhecimentos e habilidades que, em sua maioria, não são repassados em cursos profissionalizantes. A aprendizagem na prática tem se revelado, portanto, como a forma que estes profissionais encontram para melhorar sua atividade, desenvolvendo um saber próprio.

Embora seja uma profissão considerada de pouco prestígio na sociedade, em função de, geralmente, ter baixa remuneração, se comparada aos demais profissionais da área de beleza, ela não perde sua importância. Com o aumento incessante da busca pela beleza, esses profissionais têm seus serviços cada vez mais demandados, com destaque internacional. As manicures brasileiras são reconhecidas como as melhores manicures do mundo, devido à prática de trabalho desenvolvida neste País. O embelezamento das unhas, assim como o cuidado com as mesmas, também têm ganhado destaque nos meios de comunicação social. A profissão de manicure vem adquirindo crescente importância no setor de beleza, uma vez que contribui fortemente para alavancar o mercado da estética no Brasil.

O reconhecimento da atividade das manicures ainda é incipiente nas pesquisas científicas, o que amplia a importância do presente estudo. Diversas reportagens divulgadas na mídia (blogs, revistas e entrevistas com profissionais da área ${ }^{1}$ mostram que a prática de tirar a cutícula e alguns materiais brasileiros, como o alicate e os esmaltes, permitem que esta atividade receba maior reconhecimento. Fato comprovado pela crescente demanda destes profissionais no mercado internacional.

${ }^{1}$ Tais reportagens encontram-se em: <http://vilamulher.terra.com.br/manicures-brasileiras-as-melhores-do-mundo-2-1-13-104. html>; <http://www.conexaoparis.com.br/2008/11/06/manicures-em-paris/>; <http://www.bipolaridadefeminina.com. br/2011/08/parceria-alicates-da-merheje.html>. Acessos em: abr. 2012. 
A seguir, é apresentado um breve referencial teórico sobre a atividade das manicures e as formas de aprendizagem no trabalho. Após, são elucidados os procedimentos da pesquisa, a análise de informações coletadas e são feitas as considerações finais do estudo.

\section{SOBRE 0 TRABALHO DAS MANICURES}

Segundo o portal Brasil Profissões (2012), a profissão de manicure, que aqui se refere tanto ao trabalho de manicure como de pedicure, é dedicada a cuidar da saúde e do embelezamento das unhas das mãos e dos pés, por meio de técnicas, do uso de instrumentos e produtos específicos, como alicates, cortadores, lixas, esmaltes e bases. As tarefas relacionadas com esta função são realizadas respeitando critérios de higiene e estética. Dentre as principais atividades de manicures, destacam-se: corte das unhas, polimento, retirada da cutícula, esmaltagem, aplicação de cremes e esfoliantes, aplicação de unhas postiças e a esterilização dos instrumentos de trabalho (BRASIL PROFISSÕES, 2012). Os objetos de trabalho devem ser esterilizados e/ou individuais, com o objetivo de evitar a transmissão de doenças, e serem conservados em condições de uso. Como requisito para exercer a profissão, indica-se que a pessoa tenha interesse por estética, habilidade manual e facilidade de relacionamento interpessoal.

A atividade de manicure, assim como as de pedicure, cabeleireiro, barbeiro, esteticista, depilador e maquiador, é regulamentada pela Lei no 12.592, de 18 de janeiro de 2012. Esta lei reconhece, em todo o território nacional, o exercício destas profissões, cujos sujeitos exercem atividades de higiene e embelezamento dos indivíduos (BRASIL, 2012). $\mathrm{O}$ Artigo $4^{\circ}$ desta lei regulamenta especificamente a esterilização dos instrumentos, tamanha sua importância e especificidade na atuação das manicures (BRASIL, 2012). Mesmo com a regulamentação da profissão pela recente lei, não é requerida uma formação específica para atuar como manicure, por isso se diz que os profissionais se formam pelo exercício e pela prática. Existe, contudo, grande oferta de cursos profissionalizantes que buscam capacitá-los de acordo com as exigências do mercado.

Uma das principais atrações da Beanty Fair - Feira Internacional de Cosméticos e Beleza, que ocorre anualmente em São Paulo - é o espaço destinado às manicures. O Congresso de Manicures está na 9a edição e trata desde o aperfeiçoamento profissional até a apresentação do que há de mais novo no setor (ALVAREZ, 2010). Segundo o site da Beauty Fair (2012), em 2010 as manicures ficaram em terceiro lugar no ranking dos profissionais participantes da feira $(8 \%$ do total de participantes), ficando atrás somente dos cabeleireiros (65\%) e de esteticistas/ fisioterapeutas $(14 \%)$. Isso demonstra que a profissão de manicure tem crescido em números e em importância no setor.

Em 2016, ocorrerá a $12^{\circ}$ Beauty Faire, em paralelo, o $11^{\circ}$ Congresso de Manicures, onde serão abordados temas em relação à estética da atividade, como a influência e a tendência das cores e diferentes formas de aplicação das mesmas nas unhas, bem como questões sobre saúde, tanto dos clientes como dos profissionais, tais como conceitos de esterilização e identificação de patologias de pele e unha. Ainda há uma programação específica aos profissionais em relação às atividades, como saúde da coluna e, ainda, orientações técnicas, como formas de legalização para o mercado de manicures, confirmando a tendência de crescimento e consolidação desta profissão (BEAUTY FAIR, 2016).

Segundo Temperani (2011), o serviço de manicure é um dos itens mais procurados em um salão de beleza, por isso, um negócio que vem prosperando e se multiplicando são os salões especializados em serviços de manicure e pedicure. Segundo uma empresária do ramo, este tipo de estabelecimento tem crescido nos Estados Unidos e chama a atenção o papel de manicures nos salões, onde a estrela geralmente é o cabeleireiro: "em um salão como o meu, a profissional [manicure] é muito valorizada e respeitada, a estrela agora é ela". Exemplos bemsucedidos destes empreendimentos também são vistos em cidades como São Paulo (GLENIA, 2010) e Porto Alegre (ZAFFARI, 2011). Além disso, em mais uma demonstração do crescimento da profissão de manicure, foi criada a primeira empresa brasileira voltada somente aos profissionais do segmento de unhas (EMPÓRIO DAS UNHAS, 2012).

Como o material utilizado por manicures é considerado de fácil transporte, muitos profissionais atuam como autônomos, trabalham em domićlio, indo ao encontro dos clientes para realizar suas atividades, ou em suas próprias casas. Entretanto, a maioria destes profissionais atua em salões de beleza ou clínicas de estética, geralmente junto a cabeleireiros, maquiadores e outros profissionais da área (BRASIL PROFISSÕES, 2012). 
No caso de manicures que trabalham em salões de beleza, foco deste estudo, geralmente a carga horária laboral é negociada com os gerentes dos estabelecimentos. A maioria tem folga uma vez por semana e o salário é calculado de acordo com a quantidade de clientes atendidos. "Se você quer ganhar bastante, você tem que estar aqui todo o dia, toda a hora", diz uma manicure ao programa de televisão SPTV (2008), em uma reportagem sobre as manicures. A reportagem revela que a carga horária média de trabalho é em torno de oito horas diárias, em uma posição "não muito confortável” (SPTV, 2008). Por isso, alerta para a necessidade de a manicure fazer exercícios físicos e alongamentos, para ter uma condição de vida mais saudável ou menos prejudicial à saúde.

A fala da manicure entrevistada na reportagem, dizendo que "quanto mais trabalha, mais ganha" (SPTV, 2008), é um exemplo da situação de despersonalização das forças de poder (GAULEJAC, 2007), em que não mais somente os proprietários visam à maior remuneração possível. Segundo o autor, tudo é válido com relação ao trabalho, desde que possibilite mais ganhos financeiros ao empregador. Como consequência, há um impacto nas relações trabalhistas, como baixos salários, horas irregulares, menos vantagens sociais, entre outros. Todavia, sem um corporativismo trabalhista eficaz, não há resistência por parte dos trabalhadores.

$\mathrm{Na}$ referida reportagem, é feita também alusão aos cursos profissionalizantes, mas a repórter adverte que "o melhor jeito de aprender é treinar, treinar muito" (SPTV, 2008). Como esperado, a esterilização de alguns instrumentos de trabalho também ganha destaque, na afirmação de que "tão importante quanto dominar a técnica [de trabalho] é conhecer bem o processo de esterilização [dos instrumentos de trabalho]" (SPTV, 2008).

Em estudo recente realizado na cidade de São Paulo, Oliveira e Focaccia (2010) detectaram que apenas $5 \%$ dos profissionais que compuseram a amostra da pesquisa usam luvas descartáveis em suas atividades; nenhum profissional afirmou que costumava lavar as mãos com frequência; $93 \%$ não faziam uma higienização adequada nos instrumentos de trabalho; e apenas 7\% utilizavam material totalmente descartável.

A profissão de manicure envolve risco à saúde, pois lida com objetos cortantes. As infecções mais comuns que podem ser transmitidas no exercício destas atividades são as hepatites do tipo B e C e o vírus HIV, por isso, o manejo de materiais visando a preservação da saúde é necessário. No referido estudo, foi constatado que um em cada dez profissionais que participaram da pesquisa já tinha entrado em contato com o antígeno de um dos vírus da hepatite. Ratificase, pois, que a profissão de manicure envolve, dentre suas responsabilidades, não apenas o embelezamento das unhas, mas também o zelo pela saúde de clientes e profissionais.

\section{A APRENDIZAGEM NO TRABALHO}

A aprendizagem no trabalho pode ser analisada de diversas maneiras. Nicolini, Gherardi e Yanow (2003) apresentam uma discussão a respeito do estudo da aprendizagem organizacional ao qual chamaram de Aprendizagem Baseada em Práticas. Esta abordagem tem como característica a consideração do papel da linguagem e de outros artefatos culturais e materiais, bem como da natureza das interações sociais, ao invés de considerar apenas ações e atividades no processo de aprendizagem (ANTONELLO, 2011).

Estudos de comunidades de trabalho revelam que o conhecimento tende a ser distribuído entre os participantes ao invés de se concentrar dentro dos indivíduos, como propunham as teorias cognitivistas (COOK; YANOW, 1993). As teorias baseadas em prática seguem a vertente de que a aprendizagem não pode ser considerada como um processo individual (ANTONELLO, 2011). Dentre estas teorias estão a aprendizagem situada (LAVE; WENGER, 1991), a teoria ator-rede (LATOUR, 2005), a teoria da atividade cultural-histórica (ENGESTRÖM, 2001), a abordagem cultural (COOK; YANOW, 1993) e da estética (GAGLIARDI, 2004; STRATI, 2003).

O estudo de campo desta investigação teve como premissa básica que a aprendizagem das manicures está baseada na prática e, dentre as teorias existentes, analisamos a atividade das manicures sob as lentes da abordagem cultural e da estética.

\section{APRENDIZAGEM BASEADA EM PRÁTICAS}

Segundo Gherardi (2009), recentemente uma série de pesquisas da área dos estudos organizacionais e de gestão tem voltado sua atenção para as práticas. Os estudos mencionados por Gherardi (2009) 2 apresentam o rótulo dos Estudos Baseados em 
Práticas. Este termo foi utilizado para delimitar um conjunto heterogêneo de pesquisas empíricas que não apresentam uma definição comum sobre o que é 'prática' (GHERARDI, 2009).

Embora originados em contextos distintos, Nicolini, Gherardi e Yanow (2003) enfatizam que essas pesquisas corroboram a tese que o conhecimento de uma organização não pode ser considerado como o que está na cabeça de seus membros, mas como formas de expertise social, ou seja, como um conhecimento situado na ação de um contexto histórico, social e cultural no qual surge e é incorporado de diversas formas.

A grande disseminação dos estudos baseados em práticas foi acompanhada da preocupação com a perda do poder crítico enquanto o termo 'prática' foi considerado sinônimo de rotina, vantagem competitiva ou, mais genericamente, como 'o que as pessoas fazem' sem uma fundamentação teórica que ilumine o objeto de estudo (GHERARDI, 2009). Neste sentido, a referida autora elabora uma clara definição para o termo, pois considera que as práticas "não são apenas padrões recorrentes de ação (nível de produção), mas também padrões recorrentes de ação socialmente sustentada (produção e reprodução). O que as pessoas produzem em suas práticas situadas não é só trabalho, mas também a (re) produção da sociedade" (GHERARDI, 2009, p. 537). A autora assim relaciona a prática com a ação de estar no mundo.

Para Nicolini, Gherardi e Yanow (2003), no 'aqui e agora' das práticas em tempo real, o 'saber' e o 'fazer' são de difícil dissociação. Neste estudo, consideramos esta visão de prática em que não é possível distinguir estas duas ações. Assim, a aprendizagem ocorre na interação social e não pode ser restringida a uma atividade cognitiva.

Gherardi (2009) também compara o uso do termo prático ao termo amante. Segundo ela, ainda que a ação desempenhada pelo praticante seja seu ofício, todos podem ser reconhecidos por suas ações, experimentando assim o reconhecimento social de sua respectiva comunidade, que desenvolveu critérios específicos de gosto para se comunicar e refinar as formas como tais práticas são reconhecidas. Gaulejac (2007, p. 297) enfatiza que há forte relação entre o indivíduo e sua ação, ao afirmar que "quando a atividade faz sentido para o sujeito, sua adesão está adquirida". Portanto, qualquer praticante pode ser considerado um 'amante', no sentido de habitar uma prática e experimentar prazer intelectual que compartilha com os outros (GHERARDI, 2009).

Ao realizar um estudo baseado em práticas, Gherardi (2009, p. 539) menciona Gomart e Hennion (1999) 3 que propõem uma abordagem distinta para o campo:

- da ação à paixão - ao invés de focar no sujeito, o pesquisador procura descobrir como uma paixão ativa é desempenhada;

- do 'quem faz' ao 'o que ocorre' - o pesquisador deve buscar entender como os efeitos ocorrem, o que ocorre, ao invés de focar a ação;

- do fazer para o sentir - o pesquisador deve buscar compreender como algumas pessoas ajudam a ocorrência de certos eventos e como o sentimento é acompanhado.

Nicolini, Gherardi e Yanow (2003) analisam a inexistência de fronteiras das práticas, visto que se conectam com pessoas e eventos que estão distantes e são apenas parcialmente congruentes. Isto permite, "a coexistência de antigos e novos, porque eles são capazes de lidar com a mudança e a desordem ao explicar a persistência e a ordem [...]" (NICOLINI; GHERARDI; YANOW, 2003, p. 28). Por isso, entendese que a prática "é construída no seu momento e espaço, na forma de um conhecimento intuitivo, e que os julgamentos sobre o correto ou não da prática não são externos à prática, mas são formados dentro da ação, e não são apenas sustentadas pela prática, mas a constituem" (GHERARDI, 2009, p. 544-545).

O contexto de uma prática "não é dado, mas ativamente construído em vários quadros situacionais que interpretam as situações de corte do ambiente" (ANTONELLO; AZEVEDO, 2011, p. 91), sendo a prática percebida como socialmente construída. Esse fato é notório com a chegada de um novato ao ambiente, quando as práticas são compartilhadas com o indivíduo e ele passa a mudá-las, pois "ganhar o prazer do objeto de uma prática e compartilhar esse prazer com outros profissionais é algo que é aprendido e ensinado aos recém-chegados" (GHERARDI, 2009, p. 542).

\footnotetext{
${ }^{2}$ Os estudos citados por Gherardi (2009) são: Brown e Duguid (1991; 2001), Orr (1996), Gherardi (2001), Orlikowski (2000) e Yanow (2004).

${ }^{3}$ GOMART, E.; HENNION, A. A sociology of attachment: music amateurs, drug users. The Sociological Review, v. 46, n. S, p. 220$247,1998$.
} 
No contexto da aprendizagem na prática, Sennett (2009) relaciona talento com treinamento, pois há convicção de que o talento bruto pode substituir o treinamento. Para corroborar esta afirmação, são mencionados grandes gênios, como o compositor prodígio Wolfgang Amadeus Mozart (1756-1791), que ainda criança já demonstrava capacidade de se lembrar de uma quantidade impressionante de notas musicais. No entanto, o autor afirma que o compositor aprendeu a treinar sua grande memória musical inata, improvisando no teclado. Assim, por mais que as composições parecessem espontâneas, Sennett (2009) relata que as partituras eram perpassadas mentalmente e repetidas vezes por Mozart antes de serem registradas em pauta. Para Sennett (2009, p. 49), revisar repetidas vezes uma ação permite a autocrítica e também "estudar a própria prática e modulá-la de dentro para fora".

\section{ABORDAGEM CULTURAL E DA ESTÉTICA}

A análise da cultura em uma organização ocorre da mesma forma que na de uma prática (YANOW, 2000), ou seja, através de um conjunto de ações e interações que envolvem linguagem e objetos repetidos ao longo do tempo. Para Yanow (2000), quando um status ontológico é conferido ao coletivo que produz ações, linguagem, arte etc., a utilização do termo cultura aplicado à organização supera duas dificuldades. Primeiro, torna a organização uma entidade coletiva visível; e, segundo, a metáfora permite compreender que assim como uma cultura, tribo, sociedade existem, uma organização também age (YANOW, 2000).

Cook e Yanow (2001) enfatizam o viés da abordagem cultural em que a organização é vista como um agente e que suas partes não podem ser dissociadas. Os referidos autores comparam a ação de uma organização ao jogo de um time de basquete e ao desempenho de uma orquestra sinfônica, pois são atividades realizadas por grupos, as quais não podem ser concebidas individualmente. As teorias culturais situam o social em conjunto com estruturas de conhecimento simbólicas e cognitivas (ANTONELLO, 2011), ou seja, permitem visualizar um conjunto de elementos a serem levados em consideração, como o ambiente, os contextos socioeconômicos, culturais e históricos dos envolvidos. Nesta abordagem a questão principal de estudo se refere às formas de visualizar como a aprendizagem é feita coletivamente, organizacionalmente, e não à realidade coletiva da organização (YANOW, 2000). "O conceito de cultura se refere não só a um grupo de pessoas, mas a todos os artefatos por elas criados (incluindo valores, crenças, sentimentos e outras formas de significados incorporados aos artefatos)" (YANOW, 2000, p. 252). A autora afirma que, para analisar a aprendizagem organizacional culturalmente, é necessário focar o significado do trabalho que as pessoas fazem juntas.

$\mathrm{Na}$ abordagem cultural interpretativista, o conhecimento não é tido como uma atividade meramente cognitiva, presente na mente das pessoas, tampouco se trata de um conhecimento que pertence aos atores envolvidos no processo de trabalho. Nesta proposta, o conhecimento é uma atividade social, sem distinção entre o pensar e o fazer nas práticas, que são contextualizadas e interligadas à especificidade das situações. O trabalho é o conjunto de saberes em prática, o conhecimento em prática (GHERARDI, 2006; ANTONELLO, 2011).

Antonello (2011) salienta que tanto a abordagem cultural como a da estética superam a dicotomia mente-corpo e introduzem sentimentos como uma forma de saber não cognitivo. Para a autora, a compreensão cultural e simbólica da organização tem seus fundamentos e bases na abordagem da estética, em que há um julgamento de valor dado pelos sentidos. Ou seja, estética, aqui, não diz respeito a uma teoria do gosto ou do belo, mas a uma teoria da sensibilidade.

Segundo Strati (2007, p. 62), este tipo de conhecimento "é uma forma de saber (knowing) e agir dirigida pelo mundo dos sentidos [e], diz respeito ao que é percebido através dos sentidos e é julgado, produzido e reproduzido por ele". O mesmo autor afirma que este conhecimento reside no julgamento visual, auditivo, olfatório, gustatório e tátil gerando ações que apresentam forte relação com as emoções dos atores. Gherardi (2009, p. 539) complementa dizendo que a compreensão destes julgamentos estéticos se baseia em modos locais e situados de prática e, "ao mesmo tempo em que sustentam uma responsabilidade normativa da prática, constantemente refina suas modalidades".

Nesta abordagem, destaca-se o papel do corpo como instrumento de aprendizagem, ou seja, a utilização dos sentidos, do julgamento estético e do feeling ${ }^{4}$, associados a um 'conhecimento sensível'. Estão presentes ainda questões relacionadas com o conflito e com o poder

\footnotetext{
${ }^{4}$ Percepção; emoção; sentimento.
} 
no ambiente de trabalho, que também fazem parte do conhecimento organizacional de acordo com a ideia de 'espírito do lugar' (MARTIN, 2002), o qual reflete a cultura, o clima emocional, as relações sociais, o entendimento tácito, além das práticas e rotinas de trabalho.

\section{EM BUSCA DAS MANICURES}

A pesquisa foi realizada em dois salões de beleza. Um, aqui denominado de Central, localizado no bairro Centro Histórico de Porto Alegre (RS), com profissionais que atendem nas seguintes funções: cabeleireiro, auxiliar de cabeleireiro, manicure, maquiadora, depiladora e massoterapeuta. Outro, aqui denominado Hair, localizado em um bairro considerado 'nobre' da mesma Cidade, cuja equipe se constitui de duas cabelereiras, auxiliar de cabelereira, duas depiladoras, maquiadora e cinco manicures. No caso do Central, alguns desses profissionais realizam mais de um serviço, como depilação e manicure, e outros atuam como freelancer ${ }^{r}$, tais como a massoterapeuta e um dos cabelereiros. Os dois salões contam com uma recepcionista e uma profissional responsável pela limpeza, totalizando nove empregados no Salão Central e treze no Hair, porém, participaram da pesquisa apenas as profissionais manicures, totalizando sete nos dois salões: duas $^{6}$ no Central e cinco no Hair.

A seleção dos salões se deu em função da acessibilidade e da receptividade dos ambientes para realização da pesquisa. Além disso, procuramos salões que ainda não havíamos frequentado como clientes, para que não houvesse constrangimento por parte das manicures e também para que não trouxéssemos noções anteriores sobre o ambiente de trabalho dos locais escolhidos. Não tínhamos, inicialmente, como objetivo estabelecer um estudo comparativo entre os salões, mas ter possibilidade de investigar diferentes locais, além das possíveis semelhanças entre o trabalho realizado em ambos.

A estratégia de pesquisa adotada nesta pesquisa foi o estudo de caso exploratório. Segundo Yin (2003), esta estratégia se enquadra a situações em que o pesquisador deseja entender em profundidade determinado fenômeno e possui pouca influência sobre o mesmo. Como fontes de evidência, foram utilizadas técnicas etnográficas, como observação, entrevistas e diário de campo (GODOY, 2006). Apesar desta pesquisa não se configurar como uma etnografia, em função da duração das idas ao campo, utilizamos as técnicas deste tipo de pesquisa por permitirem uma compreensão simultânea das práticas e do contexto em que elas estão inseridas. O diário de campo permite o registro de tudo o que o pesquisador considera importante, incluindo eventos, atividades, interações, impressões e sentimentos (ALASZEWSKI, 2006). Buscamos utilizar técnicas que permitissem este registro de forma aprofundada.

Analisamos o trabalho e as formas de aprendizagem das sete manicures mencionadas durante o mês de dezembro de 2011 no Central, bem como durante o mês de março de 2012, no Hair. O estudo foi desenvolvido durante dois meses de muito movimento: dezembro, em função das festas de final de ano, e março, no retorno de férias, períodos mencionados pelas próprias participantes como os de maior movimento nos respectivos salões de beleza. As primeiras visitas foram realizadas em grupos de duas pesquisadoras, as demais foram realizadas com uma pesquisadora por vez. As visitas tinham durações variáveis, tendo em média 2 horas e 40 minutos e ocorreram, em média, quatro vezes por semana.

As percepções das pesquisadoras eram reportadas em um diário de campo compartilhado. Este método permite documentar aspectos particulares da vida, reconhecendo a importância do contexto no qual tais processos se desenvolvem (ZACCARELLI; GODOY, 2010). O diário de campo foi escolhido tendo em vista a capacidade de captar as peculiaridades dos acontecimentos dos salões de beleza. Havia o cuidado de evitar realizar anotações durante o período de observação, evitando assim constrangimentos das profissionais analisadas.

As informações coletadas foram analisadas durante o desenvolvimento do campo e em uma visita final, quando voltamos para tirar dúvidas remanescentes. As entrevistas eram realizadas de maneira informal,

\footnotetext{
${ }^{5}$ Termo usado para denominar o profissional autônomo que se auto emprega em diferentes empresas ou guia seus trabalhos por projetos, captando e atendendo seus clientes de forma independente.

${ }^{6}$ As manicures do salão Central desenvolviam o trabalho de manicure, pedicure, depiladora e maquiadora. Entretanto, observamos apenas o trabalho desenvolvido como manicure e pedicure. Neste estudo, optamos por denominar as manicures e as pedicures somente de manicures, conforme uma prática recorrente no setor.
} 
para confirmar algumas impressões, bem como salientar alguns pontos da observação não participante do trabalho das manicures, sobre alguma ação ou questionar determinada maneira de desenvolver o trabalho.

Tanto as entrevistas como as observações eram repassadas para o diário de campo. A observação foi realizada de modo que as pesquisadoras não interferissem no trabalho das manicures e no cotidiano do salão, apesar de nossa presença alterar o fluxo normal do ambiente. Habitualmente, ficávamos sentadas em uma cadeira na sala das manicures e observávamos como o trabalho era realizado, para posterior questionamento sobre a maneira de desempenhar a atividade, sobretudo quando as mesmas não estavam em atendimento.

Quando as manicures mudavam de ambiente, muitas vezes para atender as clientes que estavam sendo atendidas pelos cabeleireiros, seguíamos a profissional para acompanhar o trabalho desenvolvido em outro ambiente. Com base em Gherardi (2009, p. 539), mencionando o trabalho de Gomart e Hennion (1999), buscamos entender os efeitos das ações e dos eventos, ao invés de focar somente a ação, a fim de realizar um estudo baseado em práticas. Observamos como a paixão era desempenhada, tirando o foco do sujeito, ou seja, nos interessávamos pela análise de como o trabalho era desempenhado e não pelas manicures particularmente. Analisamos igualmente como a presença de outras pessoas influenciava certos eventos e como essa reação era acompanhada.

Os diários desenvolvidos pelas pesquisadoras eram relidos sistematicamente por todas, sendo lançados questionamentos e feitas análises advindas do relato das manicures e da observação em campo. As observações e análises ocorriam sob a luz do referencial teórico aqui apresentado: aprendizagem baseada em prática, focada na abordagem cultural e da estética. A partir deste referencial observamos cinco diferentes pontos: processo de aprendizagem; alimentação; saúde e segurança no trabalho; profissão da manicure; ambiente de trabalho.

A análise dos dados foi realizada através da análise interpretativa (GIL FLORES, 1994), a fim de buscar diferenças ou semelhanças nos dados coletados. Apesar de Gil Flores (1994) sugerir que, na análise interpretativa, os dados sejam segmentados e divididos em unidades relevantes de análise e que os resultados sejam apresentados em categorias, o relatório desta pesquisa foi escrito na forma de texto etnográfico. Esta forma de escrita considera a presença do investigador no desenvolvimento da pesquisa. Passamos, a seguir, a comentar e discutir os achados em campo.

\section{O SABER DO TRABALHO DAS MANICURES}

Na sequência, apresentamos a análise das informações coletadas, a qual busca verificar as diferentes formas de aprendizagem que ocorrem durante a prática do trabalho das manicures, à luz da aprendizagem baseada em práticas e da abordagem da estética e cultural.

\section{O QUE É SER MANICURE?}

O ambiente de um salão de beleza tem práticas definidas que são construídas dentro de seu contexto, pois, como afirmam Antonello e Azevedo (2011), a prática é socialmente construída. Uma das práticas compartilhadas são os hábitos alimentares, visto que as manicures, quando se inserem em um ambiente de trabalho, adotam os horários de alimentação deste local, deixando de almoçar ao meio-dia para atender clientes que ocupam este horário para irem ao salão de beleza. As manicures participantes afirmam que esta é uma prática recorrente em salões de beleza das grandes cidades e não uma peculiaridade de sua profissão, conforme constatamos nos dois locais pesquisados.

As manicures geralmente se alimentam em torno das 11 horas e, depois que termina o 'horário de almoço', fazem um lanche, em torno das 15 horas, quando têm oportunidade. Em dias de movimento, esses lanches são realizados rapidamente, entre um e outro atendimento. Esta prática já está tão incorporada nas manicures que, mesmo quando não há clientes ao meio-dia, elas não almoçam neste horário. Talvez isto ocorra, porque a qualquer minuto pode chegar um cliente e elas têm de estar disponíveis. Além disso, quando possuem uma atividade fora do salão de beleza, no horário do meio-dia, elas também não realizam a refeição no horário convencional. É como se o horário do almoço tivesse sido apagado da vida delas, pelo menos nos dias de trabalho.

Além de não terem um horário certo para se alimentarem, as refeições se resumem a pequenos lanches, em função do tempo dos atendimentos. Raras são as vezes em que são consumidos alimentos 
considerados saudáveis, como refeições completas. As refeições são, geralmente, de preparo instantâneo, sanduíches, picolés ou algum alimento trazido de casa. É frequente o consumo de guloseimas, mesmo fora do horário do lanche. As manicures entrevistadas ainda não tiveram problemas de saúde em função da má alimentação, embora tenham afirmado, principalmente as do salão Central, que tiveram aumento de peso após começarem a exercer esta profissão.

Outros cuidados que envolvem a saúde do profissional estão relacionados com as dores nas costas, em virtude da incorreta postura ao desempenhar suas funções, e com as dores nos olhos, pelo esforço que a profissão demanda, marcadamente no salão Hair. As manicures estão conscientes do alto índice de colegas que, ao longo do tempo, passaram a ter problemas visuais, tendo que recorrer ao uso de lentes de correção para exercer o trabalho.

Entre os riscos de saúde envolvendo as clientes, as manicures relataram que não tiveram que fazer vacinas para ser admitidas no salão, ou seja, não houve preocupação com isto nem por parte do estabelecimento nem das profissionais. Quando questionadas se haviam tomado todas as vacinas (no caso da hepatite B, por exemplo, são necessárias três doses e/ou o reforço), elas não souberam dizer. Isso pode ser reflexo do que é ensinado nos cursos profissionalizantes, pois a preocupação das manicures é utilizar material descartável e esterilizar os instrumentos de trabalho, conforme as lições passadas no curso.

Entretanto, os alunos não são preparados para o caso de um acidente com um cliente que tenha uma doença contagiosa, nem sobre as precauções a serem tomadas. Segundo uma das entrevistadas, em Porto Alegre, o sindicato da classe $\mathrm{f}^{7}$ faz campanhas de vacinação, no entanto ela justificou que, muitas vezes, por causa do movimento do salão, falta tempo para comparecer no dia estipulado para fazer a vacina. Observamos que não faltam oportunidades para que este tipo de cuidado com a saúde ocorra, uma vez que o Sindicato dos Salões de Barbeiros, Cabeleireiros, Institutos de Beleza e Similares do Rio Grande do Sul (SINCA) faz um trabalho de conscientização e alerta para as campanhas de vacinação, bem como o Sistema Único de Saúde (SUS) de Porto Alegre oferta a primeira vacina, assim como suas doses de reforço, de maneira gratuita para quem mencionar que realiza a atividade de manicure.

O uso de luvas descartáveis é uma prática, ensinada nos cursos profissionalizantes, esquecida no dia a dia. As manicures argumentam que perdem a sensibilidade tátil quando utilizam as luvas, portanto essas somente são utilizadas ao perceberem que podem estar colocando sua saúde em risco, ao atenderem uma cliente com micose, fungos ou corte exposto. Semelhante achado também foi evidenciado no estudo de Oliveira e Foccacia (2010). Como as manicures não têm formação técnica específica em relação à saúde das unhas, muitas vezes elas apenas observam se há fungos, para então buscar proteção. $\mathrm{O}$ trabalho da manicure é ligado à estética, por isso, elas não fazem diagnóstico deste tipo de doença, pois isso faz parte do conhecimento dos podólogos ${ }^{8}$, de acordo com uma das participantes. Elas avaliam apenas pelo aspecto: se 'o pé está muito feio', elas utilizam luvas, caso contrário, não.

De modo geral, nos dois salões, a preocupação das manicures com a higiene é evidente. A esterilização exige dedicação e conhecimento: cada alicate tem de ser lavado cuidadosamente para que o profissional não se corte com o material, depois é colocado na autoclave (estufa utilizada para esterilizar as ferramentas) para, então, ser guardado em embalagens separadas, para não contaminar os demais, até ser usado novamente. $\mathrm{O}$ conhecimento requerido na esterilização, por exemplo, não é apenas fruto da aprendizagem formal, oriunda das escolas técnicas. Isso porque é necessário um saber tátil para lavar o material cortante sem expor o corpo aos possíveis machucados. As profissionais afirmaram saber se o alicate está afiado ou não, apenas ao olhar e sentir sua lâmina, evidenciando a proposta de uma abordagem cultural interpretativista do conhecimento (GHERARDI, 2006; ANTONELLO, 2011).

Ainda assim, as profissionais entrevistadas afirmaram ter feito cursos profissionalizantes de manicure, mesmo que para exercer a profissão o certificado não seja um pré-requisito. Segundo uma das

\footnotetext{
${ }^{7}$ Há em Porto Alegre o Sindicato dos Salões de Barbeiros, Cabeleireiros, Institutos de Beleza e Similares do Rio Grande do Sul (SINCA /RS), fundado em 1931 (SINCA, 2012).

${ }^{8}$ Profissional da área de saúde de nível médio que tem como função prevenir e orientar sobre o aparecimento de lesões nos pés, como micoses, unhas encravadas, calosidades e verrugas.
} 
manicures, nesta profissão não importa se a pessoa sabe desempenhar muito bem seu trabalho, pois para ingressar no mercado, é necessário 'ter o papel', ter uma comprovação da capacitação realizada. Ainda que represente um requisito de acesso, o certificado não é o único responsável pela permanência neste concorrido mercado da beleza. Conforme já demonstrado, o crescimento deste mercado oportuniza o acesso facilitado, porém, irão se manter os profissionais que conseguem desempenhar bem seu papel, e isso é fruto não apenas dos conhecimentos técnicos, mas também de saberes oriundos da prática de trabalho, assim, aliando treinamento e talento (SENNET'T, 2009).

Um ponto que chama atenção na profissão de manicure é a realização de atividades complementares. As entrevistadas buscaram cursos envolvendo outras atividades que podem ser exercidas dentro do salão. Três das entrevistadas já realizaram curso de depilação, design de sobrancelhas, maquiagem, maquiagem de henna ${ }^{9}$, cabelereira e ainda pretendem fazer mais cursos. Uma das entrevistadas afirmou ter feito o curso de manicure mais de uma vez, pois, segundo ela, é necessário estar atenta às mudanças e às novidades do setor, alinhada com o que indica o Portal Brasil Profissões (2012).

Duas outras manicures demonstraram interesse por outros cursos, mas também desejam ingressar em uma faculdade (não necessariamente relacionada à estética), o que mostra que essa profissão também tem a característica de emprego temporário em algumas circunstâncias. Pode-se afirmar que às vezes esta atividade representa uma 'porta de entrada' ao mercado de trabalho, sobretudo para jovens ainda sem experiência de trabalho. Porém, com o desenvolvimento deste mercado, muitas vezes tal atividade torna-se definitiva, ou ainda, abre possibilidades para outras atividades dentro do setor de beleza.

Evidenciou-se que o trabalho de manicure possui um sentido de autonomia para estas profissionais. Elas afirmaram que, devido ao trabalho, adquiriram maior independência financeira e perceberam sua capacidade de aprender e de exercer uma atividade profissional. Consequentemente, isso reflete no cotidiano da família e duas manicures afirmaram ter havido aumento nos conflitos matrimoniais depois que começaram a trabalhar.

A remuneração das manicures varia conforme o salão e o material de trabalho disponibilizado. Segundo as entrevistadas, geralmente, a prática dos salões é de que, se o profissional fornece o material de trabalho (desde acetona, alicate, toalha, até água para a esterilização na autoclave), $70 \%$ da renda são destinados a ele e $30 \%$ pertencem ao estabelecimento, caso contrário, o percentual passa a ser de $50 \%$ para cada parte. Entretanto, como alguns materiais são adquiridos em grande quantidade diretamente com os fornecedores, o salão de beleza assume a compra e depois desconta diretamente da remuneração do profissional. Essa aquisição ocorre sob a responsabilidade do salão, por ser material de uso comum aos profissionais e por representar menor custo. Além disso, é necessário o número do Cadastro Nacional de Pessoa Jurídica (CNPJ) para que a compra seja realizada, portanto, como as manicures são autônomas e não possuem registro no CNPJ, dependem do salão para a aquisição de alguns materiais.

\section{A APRENDIZAGEM BASEADA EM PRÁTICAS NO TRABALHO DE MANICURE}

Desde o primeiro momento em que entram em contato com o ofício de manicure, os profissionais deste ramo são ensinados a 'aprender fazendo', uma vez que, segundo a lei que regulamenta a profissão (BRASIL, 2012), não há exigência de formação específica para atuar como manicure. Entretanto, existe uma diversidade de cursos e de treinamentos com o objetivo de promover uma base do conhecimento técnico (fisiologia das unhas e perigos de contaminação) e comportamental (conduta com os clientes).

Após as aulas expositivas, os alunos são desafiados a fazer as unhas gratuitamente em um grupo de pessoas que se cadastraram para este fim. Desta forma, os instrutores podem analisar e avaliar como os alunos desempenham a função e o que precisa ser melhorado. Segundo as manicures entrevistadas, "[o curso] nos dá a técnica, mas não nos dá a prática". Comentaram também que, independente do curso

\footnotetext{
${ }^{9}$ Nome de uma planta da qual é extraído um corante usado para colorir cabelos, tatuar o corpo e fazer maquiagem do tipo contorno dos olhos e desenho da sobrancelha.
} 
realizado, cada profissional desenvolve o seu próprio jeito de trabalhar. Este comentário mostra a importância da aprendizagem baseada em práticas, pois é no momento em que se exerce a atividade que se constrói o conhecimento, corroborando a visão de Gherardi (2009) de que a prática é situada e socialmente construída.

Outro fator que exerce influência no ofício das manicures é o ambiente de trabalho. As preocupações em relação à higiene e à forma de trabalho são, muitas vezes, reflexo das políticas do salão em que o profissional está ou, até mesmo, das condições que encontra para desempenhar suas funções. Exemplo disso são os salões que costumam solicitar que a manicure utilize luvas nos clientes para umedecer as cutículas das unhas. Embora alguns cursos ainda utilizem potes com água ou outros recursos, como o uso de cremes e jatos de água, o profissional acaba por adaptar-se às exigências do local de trabalho e/ ou dos clientes. Assim, percebemos que a cultura e o contexto exercem influência na forma de trabalho, conforme relatam os estudos de Yanow (2000).

Ao questionar sobre a adaptação das técnicas aprendidas inicialmente, percebemos que um fator crucial para buscar formas diferentes de realizar determinada atividade é o tempo. Clientes e salão demandam que a mão seja feita em até 30 minutos e que o pé fique pronto em um período aproximado de 45 minutos, independente de dificuldade ou tipo. Para estas profissionais, a obtenção de um bom salário depende do número de clientes atendidos, o que é mais um fator a influenciar a diminuição do tempo de atendimento. No caso do Hair, identificou-se, através dos relatos, sensível discordância quanto à redução do tempo de atendimento com a extinção do uso de potes com água e o emprego de algodão para umedecer as unhas e cutículas.

Dentre as adaptações das técnicas originais, uma delas percebeu, conforme ganhou experiência, que finalizar as duas camadas de esmalte em uma mão para depois passar para a outra é mais rápido do que a forma tradicional de fazer inicialmente a primeira camada em ambas as mãos e depois passar a segunda camada de esmalte. $\mathrm{O}$ método tradicional apresenta uma lógica por permitir que uma camada seque antes da seguinte. Entretanto, observamos que a manicure utiliza sua adaptação apenas quando julga ser mais oportuno. Houve um caso em que a cliente solicitou três camadas, o que demandaria maior secagem de cada uma, neste caso, a manicure optou pelo método tradicional.
Segundo as entrevistadas, estas decisões são tomadas quase que inconscientemente, assim como propõe a abordagem do conhecimento como uma atividade social, sem distinção entre o pensar e o fazer nas práticas, que são contextualizadas e interligadas à especificidade das situações (GHERARDI, 2006; ANTONELLO, 2011). Isso mostra como as práticas vão moldando a forma de exercer o trabalho, adquiridos com a experiência, mas, ao mesmo tempo, são constituídas por conhecimentos previamente existentes.

Outra adaptação realizada diz respeito especificamente ao uso da cor branca e suas tonalidades. Como este tipo de cor não demanda muita atenção com o excesso da pintura na unha, por ser uma cor clara e, algumas vezes, de difícil visualização na pele, uma das manicures decidiu não retirar o excesso de esmalte. Essa é a última etapa de realização das unhas e, quando mal executada, pode estragar a parte pronta, aumentando ainda mais o tempo total a ser dispendido. No caso da adaptação dessa manicure, o fato de não tirar o excesso final da unha, permite-lhe ganhar mais tempo.

A duração da atividade contribui ainda para determinar o uso de certas ferramentas. A bacia para o amolecimento das cutículas dos pés é um exemplo. Devido ao risco de derramar a água no chão, causando transtorno e perda de tempo até sua recolocação e a limpeza do ambiente, esta prática foi eliminada e fez emergir um novo procedimento nos salões pesquisados, evidenciando, novamente, que as práticas são sustentadas pelo ambiente, como elucida Gherardi (2009).

A nova prática consiste na utilização das luvas de plástico contendo creme hidratante, tanto para os pés como para as mãos, em substituição à bacia e ao pote com água. Isto resultou inclusive em um procedimento mais higiênico, uma vez que não envolve contato de diferentes clientes pelo mesmo material (bacia) e também mais vantajoso aos clientes, que fazem uma hidratação na pele por causa do uso dos cremes hidratantes. Há ainda uma relativa economia de água no processo, enquanto que muitas vezes o custo com as luvas pode ser repassado aos clientes, que visualizam uma melhora no procedimento.

Apesar de fortemente relacionada com o tempo, a apropriação das práticas tradicionais e sua adaptação também ocorre pelo aprimoramento dos procedimentos. Dentre as técnicas de embelezamento das unhas está a 'francesinha' que se caracteriza 
por uma pequena linha de tonalidade diferente na extremidade da unha. Os cursos ensinam diferentes formas de fazer este adorno, a ser escolhida conforme as habilidades dos profissionais. Com o tempo, uma das manicures percebeu que para cada tipo de unha há uma técnica mais adequada, uma vez que as unhas não se diferenciam somente pelo tamanho, mas também pela superfície da unha, umas que aderem melhor ao esmalte e outras mais 'lisas', mais difíceis de colorir e da tintura secar.

A experiência das manicures que participaram da pesquisa era de um e três anos na profissão, no salão Central, e de dois a quinze anos, no Hair. Observamos que mesmo a entrevistada com menos experiência já apresentava suas próprias práticas, o que mostra que uma prática não demora a ser construída. Como Gherardi (2009) analisa, as práticas são mostradas aos novatos e socializadas no ambiente, logo estão sempre em construção e, independente do tempo de profissão, estão sujeitas às transformações, seja para acompanhar as tendências do mercado e/ou para atender às especificidades dos clientes.

\section{COMPREENSÃO DO TRABALHO DAS MANICURES À LUZ DA ABORDAGEM CULTURAL E DA ESTÉTICA}

Durante a pesquisa, observamos que existem fatores culturais que influenciam o dia a dia das manicures. Apesar de o trabalho da manicure poder ser analisado de maneira individual, algumas práticas são desempenhadas e avaliadas coletivamente. Entre os diversos profissionais de embelezamento há a prática da venda de produtos de beleza, principalmente em relação às linhas de cosméticos. Uma das manicures se comportava como uma vendedora, mesmo ao falar dos produtos do salão. Outra começou a vender exclusivamente pela ênfase dada a esta prática nos cursos. Esta manicure, em especial, não demonstrava grande interesse na venda dos produtos, entretanto os vendia, pois acreditava que essa seria a forma de agir neste meio, observamos neste caso as práticas socialmente construídas no ambiente (GHERARDI 2009). Assim, percebemos a importância da prática dentro da abordagem cultural, a qual mostra que a prática molda o ambiente e se reflete no comportamento das pessoas, sendo assim considerada "o meio pelo qual o domínio é expresso e comunicado” (ANTONELLO, 2011, p. 575).
A maneira de fazer as unhas que as manicures consideram adequada segue a sequência de passos aprendida nos cursos: remoção do esmalte anterior, lixamento das unhas, retirada das cutículas, retoque dos acabamentos da unha, preenchimento com base, pintura da primeira camada de esmalte, da segunda camada e retirada dos excessos. Mesmo assim, cada uma adaptou alguns detalhes desta sequência, a fim de melhorar seu desempenho, como utilizar uma água oxigenada de pouco volume e em pequena quantidade umedecida no algodão e passar nas unhas antes de começar a pintá-las. Segundo esta manicure, este procedimento auxilia na correta limpeza e secagem dos vestígios de acetona nas unhas, o que melhora a aplicação do esmalte e, portanto, traz melhores resultados na pintura. Evidencia-se nestes casos os refinamentos das práticas correntes, já que a mesma entrevistada disse ter aprendido isso com o tempo (com a experiência) e não nos cursos técnicos de manicure.

Uma das técnicas de maior variação entre os salões diz respeito à forma de amolecimento da cutícula. Como descrito anteriormente, a técnica aprendida nos cursos de deixar as unhas de molho em água morna é adaptada devido ao risco de contaminação e transmissão de doenças. Algumas profissionais fazem uma adaptação a esta prática, inserindo no pote com água um plástico que, facilmente removível entre os atendimentos, protegendo as clientes de possíveis contaminações no instrumento. Entretanto, essa decisão não é tomada pelas manicures, mas pelo salão, confirmando a ideia de Martin (2002) sobre a influência do "espírito do lugar" nas práticas.

Nos casos estudados, o Central adotava luvas descartáveis com creme, enquanto o Hair, no início utilizava as luvas, e depois passaram a empregar apenas o algodão umedecido e aplicação direta do creme hidratante. Segundo as manicures do Central, não houve dificuldade de adequação, contudo observamos que cada profissional realizou sua própria adaptação. Uma delas aproveita o creme das luvas para uma hidratação mais profunda em mãos ou pés, enquanto limpa as cutículas. Assim, para começar a remoção da cutícula, ela rasga a luva permitindo que só os dedos fiquem de fora e o restante da mão ou pé segue sendo hidratado. Outra manicure considera rasgar a luva uma perda de tempo, ela retira a luva por completo, quando começa a remoção das cutículas.

As diferentes técnicas utilizadas pelas manicures podem ser um fator determinante para conquistar 
seus clientes, mas, provavelmente, não o principal, tendo em vista a importância de suas relações pessoais com eles. Percebemos, nas manicures, a preocupação de conversar com o cliente. Neste sentido, um artefato apresenta papel decisivo no tom da conversa do dia: a televisão. Um bom programa gera um papo interessante, que facilmente envolve todos os presentes na sala, tornando o ambiente agradável tanto para prestar quanto para receber os serviços, em ambos os salões. De certa forma, podemos relacionar o papel da televisão com o que diz Yanow (2000) sobre a importância dos artefatos conforme a interpretação dada pelas pessoas que os utilizam.

Além da conversa, a manicure necessita ter sensibilidade para compreender qual a melhor cor a ser utilizada nas unhas. Apesar de ser, muitas vezes, escolhida pelo cliente, a cor desejada pode ser obtida através da mistura de duas ou três tonalidades distintas. Questionamos as manicures sobre como aprendiam as melhores misturas e como desenvolviam esta habilidade. Segundo elas, o teste é o maior aliado para desenvolver este conhecimento. Assim, muitas vezes, a cliente, ao invés de escolher o frasco com o esmalte desejado, sugere uma cor e a manicure se empenha em obter a melhor mistura.

Neste sentido, Gherardi (2006) explica que, na abordagem da estética, as práticas estão relacionadas com julgamentos normativos constantemente negociados, no caso pelos testes e, principalmente, pela troca de experiências com os clientes. Conforme mencionado por uma das manicures entrevistadas, certas cores não ficam bem em unhas curtas, como alguns tons de vermelho, por exemplo. É necessário observar a tonalidade da pele da cliente, para ver se a cor vai 'combinar', já que, segundo uma manicure do Central, "o esmalte tem que ser a continuação dos dedos, tem que parecer que aquela cor combina tanto que é natural da tua unha”. Perguntamos como ela aprendeu estas técnicas e, novamente, a prática apareceu como aliada: "tem umas coisas que disseram no curso, outras a gente sabe, porque a gente vai aprendendo".

A manicure lida com vários instrumentos cortantes, aspira o cheiro de acetona, de esmalte ou mesmo de formol, advindo dos demais serviços do salão. Há também o desconforto físico proveniente da posição pouco ergonômica. Destaca-se ainda, que grande parte dos profissionais deste ramo é composta por mulheres e quando elas estão grávidas, por exemplo, adaptações são necessárias à atividade, uma vez que o corpo destas profissionais faz parte do seu trabalho.

Todos os sentidos são estimulados de maneira constante e formas de aprendizagem também emergem desta sensibilidade. $\mathrm{O}$ modo como as manicures aprendem a fazer seu trabalho e como avaliam uma unha bem feita está fortemente relacionado com a abordagem da estética. Segundo uma das manicures entrevistadas, o maior reconhecimento de seu trabalho está em um cliente dizer que suas unhas ficaram bonitas.

Para Gherardi (2009) este tipo de julgamento estético permite adaptação contínua, alimentando a paixão dos praticantes pelo que fazem. Além disso, outros julgamentos visuais e auditivos estão fortemente relacionados com o trabalho destas profissionais, tais como a consistência do esmalte, que mostra quão novo ele está; o formato da pele ao redor da unha, que indica uma quantidade maior ou menor de cutícula; o som do alicate; a força necessária para cortar a unha, que indica a necessidade de o instrumento ser trocado ou afiado.

Há ainda um cuidado com a passagem de ar próxima ao local de trabalho. O vento pode ocasionar o aparecimento de bolhas de ar no esmalte, prejudicando esteticamente o trabalho das manicures. Observamos que elas tentam desviar de fontes de vento como ventiladores, ar condicionado ou janelas. Durante o trabalho de uma das manicures do Central que tomava os devidos cuidados para evitar o fluxo de ar, houve o aparecimento de bolhas. Quando questionada, sentenciou que o esmalte deveria estar 'grosso', característica do produto que está terminando. Evidencia-se, mais uma vez, a presença de artefatos e elementos estéticos que interferem no trabalho das manicures, para além do embelezamento das unhas.

O trabalho da manicure é facilmente confundido com o do podólogo. Este último é responsável por cuidar da saúde dos pés, porém a profissão aqui discutida visa exclusivamente ao tratamento estético. Apesar de as atribuições serem facilmente distinguíveis, observamos que, com frequência, as manicures acabam ultrapassando esta linha tênue entre as duas atribuições, provocando, por vezes, cortes que poderiam evoluir para inflamação. Segundo uma das manicures, estes episódios também acontecem por falta de conhecimento das clientes que pedem para retirar demais a cutícula. Para as manicures entrevistadas, "a gente sabe que vai sangrar", mas não querendo desapontar a expectativa do cliente, elas seguem tirando a cutícula. Isto significa que existe um 
conhecimento tátil e visual que permite compreender a sensibilidade da pele ao redor da unha, o qual, em conjunto com outros conhecimentos, configura as atividades das manicures.

\section{CONSIDERAÇÕES FINAIS}

A sociedade, visando atender suas demandas e mesmo para preencher os papéis de prestígio social, valoriza o conhecimento ensinado nas universidades, em cursos de renome. Entretanto, notamos uma tendência: "há alguns anos, vemos politécnicos como garagistas, formados marginalizados, técnicos em declínio, diplomados de escolas de comércio sem emprego. O diploma, por mais prestigioso que seja, não é mais o passaporte para um sucesso garantido" (GAULEJAC, 2007, p. 252).

Nos estudos de Rose (2007) são evidenciados a inteligência da garçonete, o raciocínio do soldador e a estratégia do homem na linha de montagem. Estes conhecimentos, apesar de não terem sido adquiridos no ensino superior, têm valor social, embora nem sempre reconhecidos. Não é por menos que existem empresas de assistência técnica de carros que remuneram seu melhor mecânico muito além da faixa de mercado, por ele ter um conhecimento adquirido na experiência da profissão e não nos livros acadêmicos, o qual não pode ser rapidamente adquirido.

Observamos o crescimento da importância da profissão de manicure, seja no salão, no setor de beleza ou na sociedade. Fatos como a regulamentação da profissão, a abertura de salões específicos de manicure, o lugar de destaque nos eventos do setor de beleza, a grande oferta de cursos profissionalizantes e de vagas de trabalho para manicures são alguns exemplos de que esta profissão se encontra em pleno desenvolvimento no Brasil. A atividade de manicure, antes vista apenas como uma opção para o incremento da renda, a qual ocupava um lugar de coadjuvante nos salões de beleza, hoje é vista como uma profissão e como uma porta de entrada de novos clientes nos salões e clínicas de estética. Este serviço qualificado, rentável, por vezes indispensável e promotor de bem estar, vem conquistando, cada vez mais, seu espaço no concorrido mercado da beleza.

Por meio da pesquisa realizada, verificamos a existência de diversos fatores que contribuem para o aumento desse prestígio bem como um complexo desenvolvimento de habilidades e conhecimentos na prática. Notamos que as profissionais, após realizarem o curso técnico de manicure, adquirem a própria maneira de desenvolver o trabalho. $\mathrm{O}$ tempo constitui um fator importante, pois quanto mais rápido executam seu trabalho, mais clientes podem atender no dia. A escolha do tipo, a marca e o tamanho de alicate usado; a maneira como é solicitada à pessoa que afia os instrumentos; o modo de pegar a mão do cliente; e as misturas de esmaltes são práticas que são aprendidas e desenvolvidas durante o trabalho. Devido ao aperfeiçoamento das práticas, elas conseguiram otimizar seu tempo. Enquanto as manicures exercem o trabalho, elas vão refinando suas práticas profissionais, pois a prática é construída no momento e no espaço, com o conhecimento intuitivo, sendo que a noção sobre sua correção ou não ocorre dentro da ação (GHERARDI, 2009).

Notamos que a venda de produtos cosméticos por encomenda; a mudança de hábitos alimentares e o consequente aumento de peso; além dos demais problemas de saúde, como dores nas costas; a vontade de conversar com os clientes e o interesse em escutálos são práticas comuns da profissão. É como se estes fossem uma espécie de pré-requisito para poder exercer a profissão. Mas não são. As práticas são o que moldam o ambiente, pois, como explicita Gherardi (2009), ao mesmo tempo em que são ensinadas aos recém-chegados, também são aprendidas, sendo assim socialmente constituídas e (re)produzidas.

A partir da abordagem cultural e da estética, buscamos entender o trabalho das manicures. Em relação à primeira, observamos a questão da cultura das vendas, a forma de amolecimento da cutícula determinada pelo salão, os tipos de conversa presentes no ambiente que definem a relação manicure-cliente. Esta relação é, antes de tudo, uma relação de confiança no profissional não somente devido às questões de saúde, mas também pelas conversas tratadas no salão de beleza, muitas vezes de caráter confidencial. Não raramente as clientes têm preferência somente por um profissional, não aceitando fazer as unhas com outra pessoa, mostrando o reconhecimento profissional, além da identificação com a pessoa, que muitas vezes transcende a relação entre profissional e cliente. Além disso, verifica-se a importância das pessoas que se dedicam a esta profissão, pois cada vez mais estas são responsáveis pelo sustento da casa e pelo crescimento profissional desta categoria.

A abordagem da estética é visível no salão de beleza, pois as manicures aprendem sobre suas práticas a 
partir do julgamento que elas mesmas ou suas clientes fazem sobre seu trabalho. Neste tipo de profissão, em que é necessária concordância na avaliação estética do trabalho, observa-se a necessidade do desenvolvimento de um conhecimento sensível, para que a profissional compreenda não só a 'necessidade do cliente', mas também o que se considera como um bom trabalho. Percebemos diversas formas de fazer a avaliação do trabalho, como o uso da capacidade visual e de critérios sensitivos. $\mathrm{Na}$ avaliação do resultado final pelo cliente, podem ser considerados o tipo e a complexidade da unha, a espessura das cutículas, a escolha da cor mais adequada etc.

Durante a pesquisa, frequentemente nos deparamos com situações em que o conhecimento técnico era negligenciado ou modificado em prol da incorporação de novos conhecimentos, sejam eles de caráter financeiro, comportamental ou referentes ao modo de desenvolver o trabalho. Tais conhecimentos são integrados em uma mistura de antigos e novos conhecimentos e experiências, resultando em novas práticas e aprendizados, ou como salienta Gherardi (2009) são formados dentro da ação, constituindo a própria prática.

A partir da teoria baseada em prática é possível analisar esses contextos menos reconhecidos, mas com expressiva contribuição social bem como valorizar o conhecimento dito informal e aprendido na interação e no desenvolvimento do próprio trabalho, visto que outras teorias sobre essa temática não dão espaço para o reconhecimento de um assunto que está naturalizado na sociedade.

Frente à expressiva quantidade de estudos que enfatizam os estudos focados na aprendizagem formal nas organizações, por meio de treinamento e cursos, foi possível analisar a importância da abordagem cultural e da estética, além da teoria baseada em práticas na aprendizagem das pessoas ao desempenharem seu trabalho. Isso sinaliza o valor que a aprendizagem tem nas organizações e pode vir a contribuir no intuito do desenvolvimento e valorização de novos conhecimentos, por meio do reconhecimento e institucionalização das práticas.

\section{Referências}

\section{ALASZEWSKI, A. Using diaries for social} research. SAGE Publications, 2006.

ALVAREZ, L. Beauty Fair 2010 - Cabelos, Estética, Manicure, Maquiagem e Negócios. Vila Batom.

24.08.2010. Disponível em: < $\underline{\text { http://vilamulher.terra. }}$ com.br/beauty-fair-2010-cabelos-estetica-manicuremaquiagem-e-negocios-2-1-12-285.html $>$. Acesso em: 05 fev. 2012.

ANTONELLO, C. Organizações culturais e a aprendizagem baseada em práticas. In:

Aprendizagem Organizacional no Brasil. Porto Alegre: Bookman, 2011. p. 565-582.

ANTONELLO, C. S.; AZEVEDO, D. C. Aprendizagem Organizacional: explorando o território das teorias culturais e baseadas em práticas. In: ANTONELLO, C. S.; GODOY, A. S. (Eds.) Handbook de Aprendizagem Organizacional. Porto Alegre: Bookman, 2011, p. 89-113.

BEAUTY FAIR. A Feira. Disponível em: < $\underline{\text { http:// }}$ beautyfair.com.br/afeira/index.html > . Acesso em: 05 fev. 2012 e 08 jan. 2015.

BEAUTY FAIR. $11^{\circ}$ Congresso de Manicures. Disponível em: <http://www.beautyfair.com.br/ feira-beauty-fair/11o-congresso-de-manicures $/>$. Acesso em: 12 mar. 2016.

BRASIL. Lei No 12.592, de 18 de janeiro de 2012. Sobre o exercício das atividades profissionais de Cabeleireiro, Barbeiro, Esteticista, Manicure, Pedicure, Depilador e Maquiador. Diário Oficial [da] República Federativa do Brasil, Brasília, DF, 18 jan. 2012. Disponível em: <http://www.planalto. gov.br/CCIVIL_03/_Ato2011-2014/2012/Lei/ L12592.htm>. Acesso em: 22 jan. 2012.

BRASIL PROFISSÕES. Portal. Disponível em: $<$ http://www.brasilprofissoes.com.br/profissoes/ manicure>. Acesso em: 20 jan. 2012.

BROWN, J. S.; DUGUID, P. Organizational Learning and Communities of Practice: Toward a Unified View of Working, Learning and Bureaucratization.

Organization Science 2: 40-57. 1991.

BROWN, J. S.; DUGUID, P. Knowledge and Organization: A Social-practice Perspective. Organization Science 12(2): 198-213. 2001.

COOK, S. D.; YANOW, D. Culture and organizational learning. Journal of Management Inquiry, v. 2, n. 4, p. 373-390, 1993. 
COOK, S. D.; YANOW, D. Culture and

Organizational Learning. Journal of Management

Inquiry, v. 2, p. 373-390, 2001.

DEJOURS, C. O trabalho como enigma. In:

LANCMAN, S., SNELWAR, L. I. (orgs).

Christophe Dejours: da psicopatologia à

psicodinâmica do trabalho. Rio de Janeiro: Editora

Fiocruz; Brasília: Paralelo 15, 2008.

EMPÓRIO DAS UNHAS. Sobre. Disponível em: $<$ http://www.emporiodasunhas.com.br/sobre/>. Acesso em: 05 fev. 2012.

ENGESTROM, Y. Expansive Learning at Work: Toward an activity theoretical reconceptualization. Journal of Education and Work, v. 14, n. 1, p. 133156, fev 2001.

GAULEJAC, V. Gestão como doença social: ideologia, poder gerencialista e fragmentação social. Aparecida, SP: Ideias \& Letras, 2007.

GHERARDI, S. Practice-based Theorizing on Learning and Knowing in Organizations: An Introduction. Organization 7(2): 211-23. 2001.

GHERARDI, S. Organizational knowledge: the texture of workplace learning. London: Blackwell, 2006.

GHERARDI, S. Practice? It's a Matter of Taste! Management Learning, v. 40, n. 5, p. 535-550, 21 out 2009 .

GIL FLORES, J. Aproximación interpretativa al contenido de la información textual. En: Análisis de datos cualitativos: aplicaciones a la invesigación educativa. Barcelona: PPU, 1994. p. 65-107.

GAGLIARDI, P. Explorando o lado estético da vida organizacional. In: CLEGG, S.; HARDY, C.; NORD, W. R. Handbook de estudos organizacionais. São Paulo: Atlas, 2004.

GLENIA, F. Salões apostam em 'especialização em unhas' para conquistar clientes. Economia e Negócios: G1. 27.09.2010. Disponível em: $<$ http://g1.globo.com/economia-e-negocios/ noticia/2010/09/saloes-apostam-em-especializacaoem-unhas-para-conquistar-clientes.html>. Acesso em: 05 fev. 2012.

GODOY, A. S. Estudo de caso qualitativo. In: GODOI, C. K.; BANDEIRA-DE-MELLO, R.; SILVA, A. B. (orgs.). Pesquisa Qualitativa em Estudos Organizacionais: paradigmas, estratégias e métodos. São Paulo: Saraiva, 2006, p. 115-146.
LATOUR, B. Reassembling the Social: an introduction to Actor-Network-Theory. [S.l.]: Oxford University Press, 2005. p. 301

LAVE, J.; WENGER, E. Situated learning: legitimate peripheral participation. Cambridge: Cambridge University Press, 1991.

NICOLINI, D.; GHERARDI, S.; YANOW, D. Introduction: Toward a practice-based view of knowing and learning in organizations. In: NICOLINI, D.; GHERARDI, S.; YANOW, D. (Eds.). Knowing in organizations: a practice-based approach. NY: ME Sharpe Armonk, 2003. p. 3-31.

MARTIN, P. Y. Sensations, bodies, and the 'spirit of a place': aesthetics in residential organizations for the elderly. Human Relations, v. 55, n. 7, p. 861-885, 2002.

OLIVEIRA, A. C. D. S.; FOCACCIA, R. Survey of hepatitis $\mathrm{B}$ and $\mathrm{C}$ infection control: procedures at manicure and pedicure facilities in São Paulo, Brazil. Brazilian Journal of Infectious Diseases [online]. 2010, v.14, n.5, p. 502-507. Disponível em: <http:// dx.doi.org.ez45.periodicos.capes.gov.br/10.1590/ S1413-86702010000500013>. Acesso em: 25 jan. 2012.

ORLIKOWSKI, W. J. Using Technology and Constituting Structures: A Practice Lens for Studying Technology in Organizations. Organization Science 11(4): 404-28. 2000.

ORR, J. Talking About Machines: An

Ethnography of a Modern Job. Ithaca, NY: Cornell University Press. 1996.

ROSE, M. O Saber do Trabalho: valorização da inteligência do trabalhador. São Paulo: Editora SENAC São Paulo, 2007.

SENNETT, R. O Artífice. Rio de Janeiro: Record, 2009.

SINCA. Sindicato dos Salões de Barbeiros, Cabeleireiros, Institutos de Beleza e Similares do Rio Grande do Sul. Disponível em: <http://www.sincars. com.br/>. Acesso em: 01 mar. 2012.

SPTV. Mercado de trabalho: conheça a profissão de manicure. SPTV, Rio de Janeiro: Rede Globo, 19 de novembro de 2008. Programa de TV. Disponível em: <http://video.globo.com/Videos/Player/ Noticias/0,,GIM913581-7823-MERCADO+DE+T RABALHO+CONHECA+A+PROFISSAO+DE+ MANICURE,00.html>. Acesso em: 21 jan. 2012.

STRATI, A. Knowing in practice: aesthetic 
understanding and tacit knowledge. In: NICOLINI, D.; GHERARDI, S.; YANOW, D. (Eds.). Knowing in organizations: a practice-based approach. NY:

ME Sharpe Armonk, p. 53-75, 2003.

STRATI, A. Sensible Knowledge and Practice-based Learning. Management Learning, v. 38, n. 1, p. 61 77, 1 fev 2007.

TEMPERANI, M. Salão especializado só em unhas é a mais nova opção de negócio no setor de beleza. Notícias: Beanty Fair. 15.12.2011. Disponível em: < http://www.beautyfair.com.br/manicure/ noticia/1822.html>. Acesso em: 05 fev. 2012.

YANOW, D. Seeing Organizational Learning: A "Cultural" View. Seeing Organizational Learning, v. 7 , n. 2, p. 247-268, 2000.

YANOW, D. Translating Local Knowledge at Organizational Peripheries. British Journal of Management 15(S1): 9-25. 2004.

YIN, R. Case study research: design and methods. 3. ed. California: SAGE Publications, 2003.

ZAFFARI, F. O esmalte ganha casa própria. Estilo Próprio: Portal ClicRBS. 03.12.2011. Disponível em: $<\underline{\text { http://wp.clicrbs.com.br/ }}$ fernandazaffari/2011/12/03/o-esmalte-ganha-casapropria/?topo $=13,1,1,18,13 \#$ comments $>$. Acesso em: 05 fev. 2012.

ZACCARELLI, L. M.; GODOY, A. S. Perspectivas do uso de diários nas pesquisas em organizações Perspectives of using diaries in organizational research. CADERNOS EBAPE. BR, v. 8, n. 3, p. 550-563, 2010. 